\title{
ESTRATÉGIAS DE REDUÇÃO DE CUSTOS DE NÃO QUALIDADE NA INDÚSTRIA DE COUROS
}

\author{
STRATEGIES FOR REDUCTION OF QUALITY COST IN THE LEATHER \\ INDUSTRY \\ Diego Augusto de Jesus Pacheco ${ }^{1,}$, Éderson Luís dos Santos²
}

\begin{abstract}
RESUMO
O objetivo dessa pesquisa foi reduzir os custos da não-qualidade em um sistema de produção de curtimento de couros. A pesquisa é baseada no estudo de caso de uma empresa brasileira que vem enfrentando instabilidade financeira causadas pelos problemas de qualidade do sistema produtivo. Os resultados evidenciaram que a variável de controle maciez do couro é responsável por $80 \%$ dos custos de não qualidade da produção. Os resultados da pesquisa evidenciaram ainda dificuldades internas na aceitação da implantação dos controles quantitativos de qualidade implantados pelos funcionários do nível operacional da fábrica. De forma geral, a pesquisa discutiu a importância para as empresas do segmento de couro de investigar as causas-raízes dos problemas de qualidade visando reduzir custos com retrabalhos e devoluções de clientes. Dentre as implicações para as empresas da indústria da manufatura de couro, percebeu-se a necessidade de aprimorar as capacidades dos colaboradores com novas técnicas de gestão da qualidade para atender à crescente competitividade do mercado.
\end{abstract}

Palabras Clave: Curtimento de couro, Custos da não-qualidade, Ferramentas da qualidade.

\section{ABSTRACT}

The objective of this research was to reduce the non-quality costs in a production system of leather tanning. The research was based on the case study of a Brazilian company that has been facing financial instability caused by quality problems of the production system. The results showed that the leather softness variable is responsible for $80 \%$ of the nonquality costs. The findings of the research also revealed internal difficulties in accepting the implementation of quantitative quality controls implemented by employees at the plant's operational level. Overall, the research discussed the importance for leather companies

\footnotetext{
${ }^{1}$ Departamento de Engenharia de Produção, Centro Universitário Ritter dos Reis - UniRitter, Porto Alegre, Rio Grande do Sul, Brasil. orcid.org/0000-0003-4453-7216

2 Departamento de Engenharia de Produção, Faculdades Integradas de Taquara, Rio Grande do Sul, Brasil. ederson.Is.santos@gmail.com. orcid.org/0000-0001-8536-5196
} 
investigating the root causes of quality problems in order to reduce costs with rework and customer returns. Among the implications for companies in the leather manufacturing industry, was the need to improve the skills of employees with new quality management techniques to meet the growing competitiveness of the market.

Keywords: Leather tanning, Costs of non-quality, Quality tools.

\section{INTRODUÇÃO}

No momento atual da economia brasileira em crise, as empresas de diversos setores foram afetadas pelo cenário de recessão econômica. Como consequência, as empresas buscam diminuir os custos da não qualidade. Ou seja, os custos que as empresas pagam como consequência da má qualidade no produto, a qual pode ser identificada internamente nos processos produtivos, ou externamente quando o cliente faz uma reclamação de uma não conformidade no produto. Nesse sentido, Soccol \& Gomes (2011) corroboram afirmando que a boa prática de reduzir os custos de não-qualidade, será um diferencial entre as empresas e para conquistar a confiança, não perder seus clientes e ter uma saúde financeira saudável.

A fabricação de um produto com qualidade, sema ocorrência de custos adicionais se tornou um requisito indispensável para a sobrevivência das empresas (Roldan et al., 2013). Deste modo, os gestores dedicam-se a implementação de ferramentas da qualidade para o aperfeiçoamento e melhoria contínua em seus processos e produtos (Campos, 2016). Além disso, os avanços tecnológicos levaram a conjuntos de dados relacionados à qualidade industrial maiores, exigindo métodos de monitoramento de processos (Peres \& Fogliatto, 2018).

Para suportar as práticas da qualidade, algumas normas padronizadoras de serviço ou produto, como a ISO 9001, tem como um de seus principais requisitos a busca continua pela melhoria da qualidade. A maioria dos problemas das empresas, podem ser analisados e resolvidos a partir da utilização de ferramentas da qualidade, possibilitando descobrir a verdadeira causa dos desperdícios ou insucessos, gerados no processo menciona (Oliveira et al., 2016).

Com essa finalidade, tradicionalmente são utilizadas as ferramentas da qualidade, tais como o diagrama de Causa e Efeito, Gráficos de Pareto, entre outras (Olivares et al., 2011). Além disso, ferramentas do Lean Manufacturing e da Teoria das Restrições podem ser combinadas de forma integrada com as ferramentas da qualidade para potencializar os resultados. Durante a implementação das ferramentas, as empresas identificam algumas dificuldades, tais como a limitação de recursos humanos, recursos financeiros, falta de comprometimento gerencial, resistência a mudanças e rotatividade de funcionários (Kirner, 2010). Já o controle estatistico de processos é uma solução desenvolvida para coletar e analisar dados com facilidade, permitindo o monitoramento do desempenho e solução de problemas (Godina et al., 2018).

Contudo, enquanto alguns setores industriais possuem maior maturidade e infusão das práticas da qualidade, outros setores estão em um nível mais baixo de implantação. A indústria automotiva, por exemplo, pode ser considerado um segmento com maior maturidade. Já outros segmentos, como a indústria da manufatura do couro, ainda necessidade atingir um maior estágio de implantação da práticas de melhoria da qualidade (Vrabič \& Aloja, 2013). De forma a corroborar a necessidade de mais pesquisas envolvendo a temática dos custos da não qualidade na indústria de curtimento de couros, a pesquisa por estudo nas bases de dados Scopus e Scielo pela palavras chave 'curtimento de couro' e 'custos da não qualidade' não retornou nenhum estudo integrando ferramentas da qualidade, com as ferramentas Lean e da Teoria das Restrições. 
Assim sendo, este trabalho pretende analisar e reduzir os custos da não-qualidade dentro de um processo produtivo de curtimento de couro, identificando, classificando e quantificando os defeitos gerados. O estudo é de importância para as empresas deste segmento por duas razões principais: (i) devido à necessidade de melhoria nas margens de lucros e de produtividade desse segmento de negócio; (ii) devido à baixa maturidade da implantação das ferramentas da qualidade nesse setor. Este artigo, foi estruturado na seguinte forma. Após feita a apresentação do problema de pesquisa, a seção dois apresenta o referencial teórico e na seção três os procedimentos de pesquisa e coleta de dados são apresentados. Na seção quatro os resultados da análise dos custos de qualidade na empresa são apresentados. A seção seguinte faz a análise e discussão dos resultados. Por fim, o artigo encerra com a seção seis, onde são feitas as conclusões sobre o estudo.

\section{Mensuração dos custos da Qualidade}

Os motivos que levam a maioria das empresas a mensurar os seus custos de qualidade são motivados, de maneira geral pela preocupação gerencial de, a partir do conhecimento do montante dos custos da qualidade, identificar a oportunidade de redução de custos e avaliar o desempenho de empresa em termos de qualidade (Packer \& Suski, 2010; Vasconcelos et al., 2009). Silva e Severiano Filho (2011), afirmam que os motivos que levaram as empresas a adotarem um enfoque gerencial ao sistema de custos da qualidade foram os seguintes: consideram a mensuração dos custos da qualidade, um indicador de gestão da qualidade, avaliação de desempenho ou avaliação de rentabilidade, por meio dos valores dos custos da qualidade, identificam oportunidade de redução de custos ou redução de prazos e consideram os custos da qualidade um instrumento auxiliar na busca de melhorias continuas, para sobrevivência da empresa.

Pode-se dizer que os custos relacionados às falhas internas são todos aqueles ocorridos devido a algum erro do processo produtivo. Tanto no caso das falhas humanas ou das falhas mecânicas, quando mais cedo os erros forem detectados, menores serão os custos envolvidos para corrigi-los (Cociorva et al., 2010). Os custos relacionados as falhas externas, são aquelas falhas no produto ou serviço, quando se acham no mercado ou são obtidos pelo consumidor final, não conformidades externas geram custos intangíveis, como destruição da imagem e confiabilidade da empresa (Pasquini, 2013).

Por fim, conforme Pintos e Gomes (2011) afirmam em seus estudos que, os custos da não-qualidade tanto internas como as externas, poderão ser definidos como custos da máqualidade. De maneira similar, estão os custos de avaliação, que derivam da necessidade de separar o ruim do bom. Ainda que tenham sido geradas pelas atividades da função qualidade, esses custos só passaram a existir em consequência de falhas.

\section{As ferramentas da Qualidade}

As ferramentas da qualidade facilitam encontrar os problemas e achar as suas causas raiz, permitem que a melhoria contínua seja alvo constante para uma organização, através da utilização das ferramentas da qualidade, assim conseguimos listar e quantificar os problemas que estão gerando o maior custo da não-qualidade, relata (Pacheco \& Rodrigues, 2011).

Silva e Sasaki (2011) ressalta que, as ferramentas de qualidade têm um grande potencial no uso de identificar as causas raízes dos problemas e para a solução destes, porém é de grande importância que elas sejam interpretadas de forma corretas, para que uso delas seja bem sucedido. Masques (2010), complementa que as ferramentas sempre devem ser encaradas como meio para atingir as metas e objetivos, elas podem ser usadas para identificar e melhorar a qualidade, enquanto a meta é onde queremos chegar.

Coletti et al.. (2010), exaltam que o Gráfico de Pareto é uma forma que nos permite identificar os problemas, resolver a qual dar prioridade, também estabelece metas numéricas, viáveis 
a serem alcançadas. É um gráfico que ordena as frequências das ocorrências da maior para menor, que tem como objetivo priorizar os problemas, com o princípio de que $80 \%$ das consequências advêm de $20 \%$ das causas (Zanoni et al., 2006).

O Gráfico de Pareto ajuda a agrupar os defeitos, baseados na sua respectiva classificação, ressaltando as categorias mais comuns e a soma destas no próprio gráfico (Kalinowski \& Costa, 2015). Paladini (1998), conclui que o Gráfico de Pareto, por ser uma ferramenta que classifica as causas que atuam em um dado processo, de acordo com seu grau de importância, é uma das técnicas mais utilizadas nas empresas, para saber quais problemas estão dando mais impacto no processo ou mais custos, aquele custo que não agrega valor ao produto.

Quanto ao diagrama de Ishikawa, Júnior (2010), transcreve que essa ferramenta consiste em uma forma gráfica que usa como metodologia representar fatores de influência (causas) sobre um determinado problema (efeito). Conforme Gonçalves (2011), essa ferramenta foi desenvolvida na década de 40 por Kaoru Ishikawa, na Universidade de Tóquio. Uma das vantagens é a possibilidade de atuar de modo mais especifico no detalhamento das causas possíveis (Almeida \& Matias, 2015).

O Diagrama de causa-efeito, pode ser aplicado na situação de melhoria ou para encontrar as possíveis causas do problema, ele pode ser elaborado nesses seguintes passos: determinar o problema ser estudado, relatar sobre as possíveis causas e registrá-las no diagrama, construir o digrama agrupando as causas em "6M" (mão de obra, método, matéria-prima, medida e meio-ambiente), analisar o diagrama, a fim identificar as causas verdadeira e a correção

Outra ferramenta útil para encontrar causas raízes é a Árvore de realidade atual (ARA). A ARA é uma ferramenta da Teoria da Restrições que possibilita aprofundar o conhecimento de uma organização e seu ambiente, identificando os problemas centrais, é uma ferramenta baseada na lógica de causa e efeito, que comunica os relacionamentos casuais existentes, em uma determinada situação de interesse, explica (Silva \& Sasaki, 2011).

A construção da ARA, deve ser feita em grupos interfuncionais, proporcionando efetiva comunicação dos principais problemas da empresa e um entendimento comum desses problemas (Lacerda et al., 2011). Tais autores ainda afirmam que, para que a ARA esteja concisa e correta, é obrigatório haver consistências. As consistências são utilizadas para validação e nivelamento do entendimento da ARA. Segundo Santos (2012), as flechas são os indicativos de suficiência, isto é, para que ocorra um determinado efeito indesejado é necessária a ocorrência de outro (individualmente, simultaneamente ou ambos).

Para Wanderley e Cogan (2012), a ARA fornece mecanismos para identificar o impacto de políticas, procedimentos e ações na organização, comunicar clara e concisamente, a causalidade dessas políticas, procedimentos e ações, identificar o problema central em uma situação, permitir a criação de um clima favorável de relação frente aos problemas. Novaes (2015), ainda ressalta ainda que a ARA deve ser construída de maneira top-down, entretanto deve ser lida e compreendida de uma forma bottom-up. Uma das formas de realizar a consistência é apresentá-la a outras pessoas, que não participaram da construção da árvore. O relatório A3 é uma ferramenta Lean que tem como origem o tamanho da folha, utilizada para os registros do projeto de melhoria, ou seja, uma folha no formato A3 (Silva \& Sasaki, 2011). Conforme Arantes e Giacaglia (2013), a ferramenta teve forte influência nos resultados obtidos pela Toyota, nos últimos 50 anos, sendo usado para tratar e resolver problemas de todos os tipos. O objetivo é, fazer com que todos os que enfrentam o problema, desafio ou projeto enxerguem a questão a ser resolvida, por meio de uma mesma lente, uma única folha de papel A3 (Brandi et al., 2012).

Trata-se de uma ferramenta que direciona os solucionadores de problemas a uma 
compreensão mais profunda do problema ou da oportunidade (Oliveira et al., 2016). Além disso, proporciona o aprendizado e acúmulo de conhecimento, ajudando as pessoas a aprender e como aprender (Hilgemberg, 2015). A partir da simplicidade, do poder de síntese e foco e da estrutura lógica, a metodologia A3 permite que somente as informações mais críticas sejam compartilhadas, evitando longos relatórios de difíceis visualização, conforme explica (Santos, 2014).

O relatório deve ser interpretado e lido a partir do canto superior esquerdo ao canto inferior direito (Ito \& Claro, 2011). O relatório apresenta do lado esquerdo as etapas referentes ao planejamento, enquanto o lado direito refere-se ás etapas de fazer, verificar e agir. A figura 1 , mostra as etapas a serem realizadas no relatório (Rosa et al., 2016).

\section{MATERIAIS E MÉTODOS}

O objetivo desse estudo foi analisar e reduzir os custos da não-qualidade dentro de um processo produtivo de curtimento de couro, identificando, classificando e quantificando os defeitos gerados. A empresa em análise tua no setor de curtimento do couro bovinos, com o foco na produção de couros acabados e semiacabados. Seu principal produto são os tapetes, classificados em naturais, serigrafados e tingidos.

A presente pesquisa possui natureza aplicada e foi baseada na aplicação de estudo de caso, de acordo com as diretrizes de Lakatos e Marconi (2003). Após coletar os dados em documentação interna da empresa, a pesquisa identificou as causas que geram o custo da não-qualidade aplicando abordagens qualitativas e quantitativas.

Essa pesquisa é considerada descritiva, dados que foi realizada a partir de uma análise documental. A principal fonte de informações foi o setor de classificação do produto acabado de produção de couro. Foram mensurados os custos com os produtos não conformes. Após está etapa documental analisada, para descobrir os possíveis problemas que estão gerando um custo da não-qualidade, foi utilizado o gráfico de Pareto, permitindo assim identificar quais os problemas e resolver a qual dar importância.

Em seguida, com os problemas já definidos, foi aplicado o diagrama de Ishikawa para identificar as causas dos problemas a partir da lógica dos $6 \mathrm{Ms}$. $\mathrm{Na}$ etapa seguinte, foi elaborado o diagrama da ARA, que permitiu relacionar as causas com os efeitos, e encontrar a causa raiz do problema que impactou na qualidade do produto e na sua produção. Por fim, com o desenvolvimento do relatório A3 foi feito plano de ação para solucionar o problema enfrentado no processo de curtimento do couro.

\section{RESULTADOS E DISCUSSÃO}

Os problemas encontrados nos lotes de couros acabados, foram coletados durante o mês de outubro, no setor de classificação do produto acabado, registrados em uma planilha no Excel e calculados os custos desses produtos não-conformes, como se pode observar na Tabela 1. 
Tabela 1. Relatório de problemas no mês de outubro

Relatório de problemas do encontrado no mês de Outubro/2016

Custo do Metro do couro

$\$ 18,30$

Defeito

Couro com a maciez inferior a cartela padrão especificada pelo cliente.

Flor solta

Veia

Manchas

Carrapato

Espessura fina

Cor fora do especificado

Ruga

Total
Quantidade

Custo

(\$)

$\begin{array}{cc}1552 & 21800 \\ 64 & 1170 \\ 55 & 1006,10 \\ 44 & 804,88 \\ 43 & 785,60 \\ 42 & 768,30 \\ 36 & 658,54 \\ 22 & 402,44 \\ 1858 & 26067\end{array}$

Após ter os dados coletados, foi elaborado o Gráfico de Pareto, que permitiu identificar qual problema e resolver a qual dar prioridade, conforme o custo mais alto, utilizando o princípio ( $80 \%$ das consequências, advêm de $20 \%$ das causas), como está ilustrando a Figura 1.

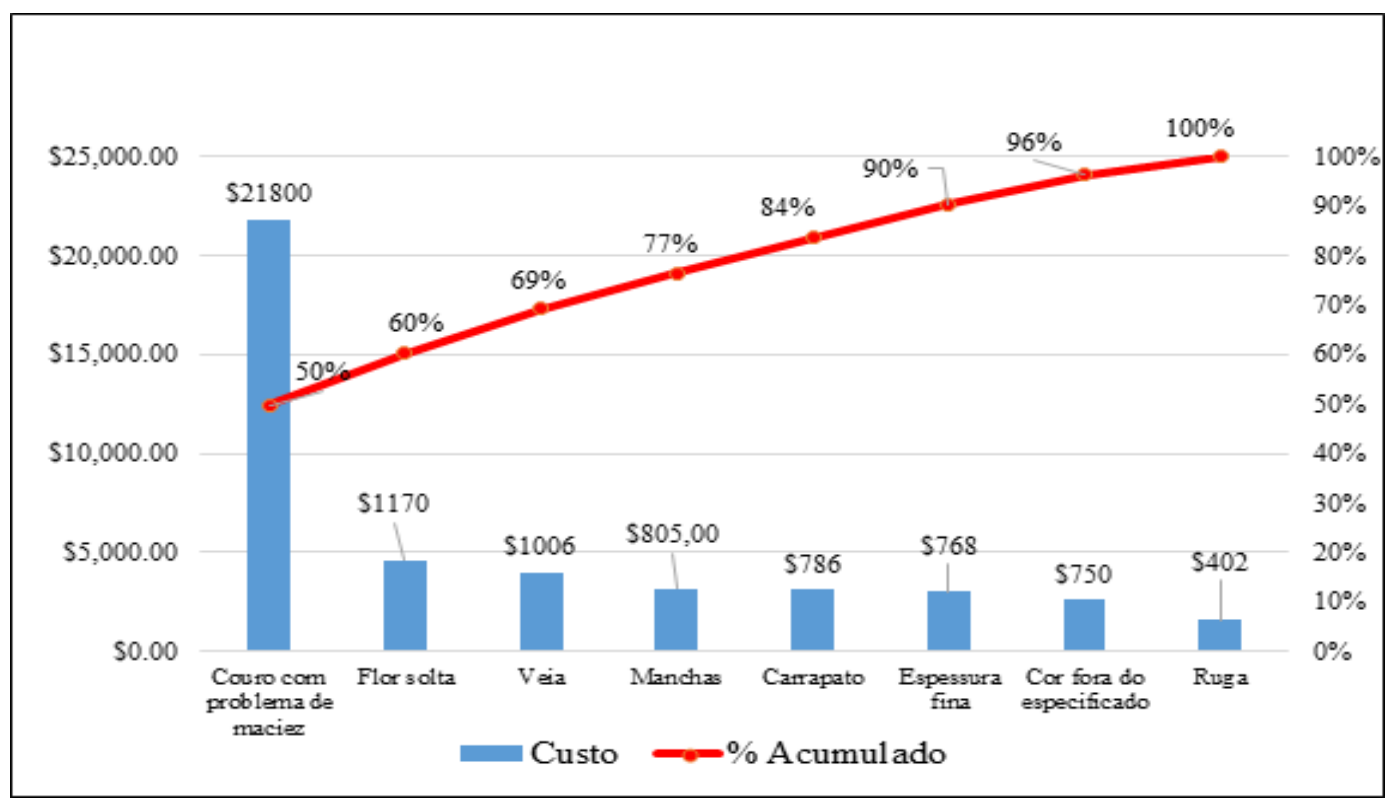

Figura 1. Gráfico de Pareto priorizando os problemas.

Com o gráfico de Pareto, podemos analisar que $80 \%$ dos problemas ocorridos no mês de outubro estão relacionados como a cabeça do couro com o toque duro. Tal problema teve 
a implicação de um custo de $\$ 21800,00$. Com essa análise identificamos qual problema ocorre com mais frequência, e qual vamos solucionar, identificando as possíveis causas.

\section{Máquina}

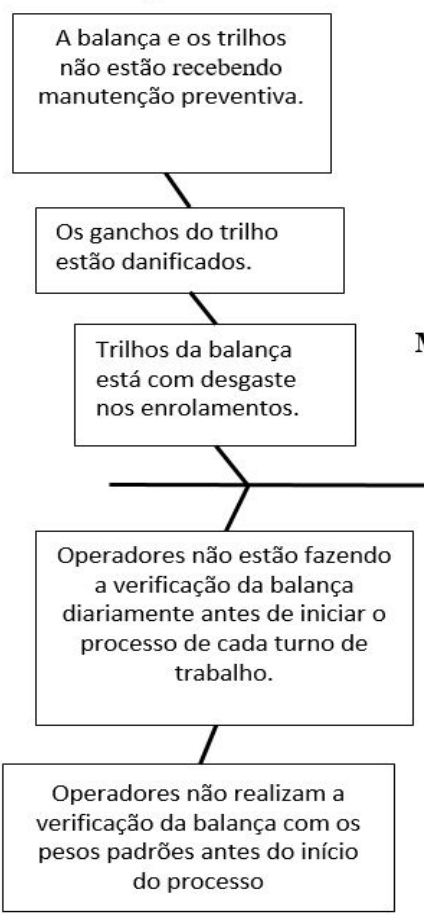

Método

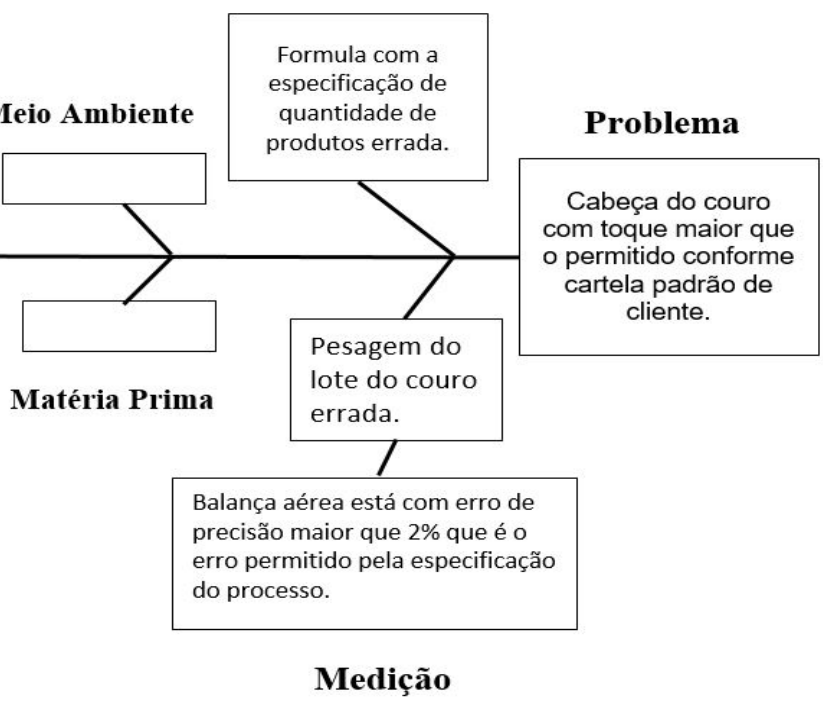

Figura 2. Diagrama de Ishikawa

Tendo o problema já priorizado para resolver com o auxílio do gráfico de Pareto, o segundo passo consistiu em determinar as causas do problema. Foi aplicado nessa etapa o Diagrama de Ishikawa. A figura 2, apresenta o Diagrama de Ishikawa com as possíveis causas identificadas, conforme os 6Ms. Em cada categoria foi colocado a sua possível causa referente ao problema encontrado. Para essa elaboração, foi realizada uma reunião com os gestores da empresa. Como resultado, na categoria máquina foram encontradas três causas, em mão de obra foram encontradas duas causas, em método foi encontrada uma causa, e em medição duas causas. Relacionadas com matéria prima e meio ambiente não encontramos nenhuma causa. 


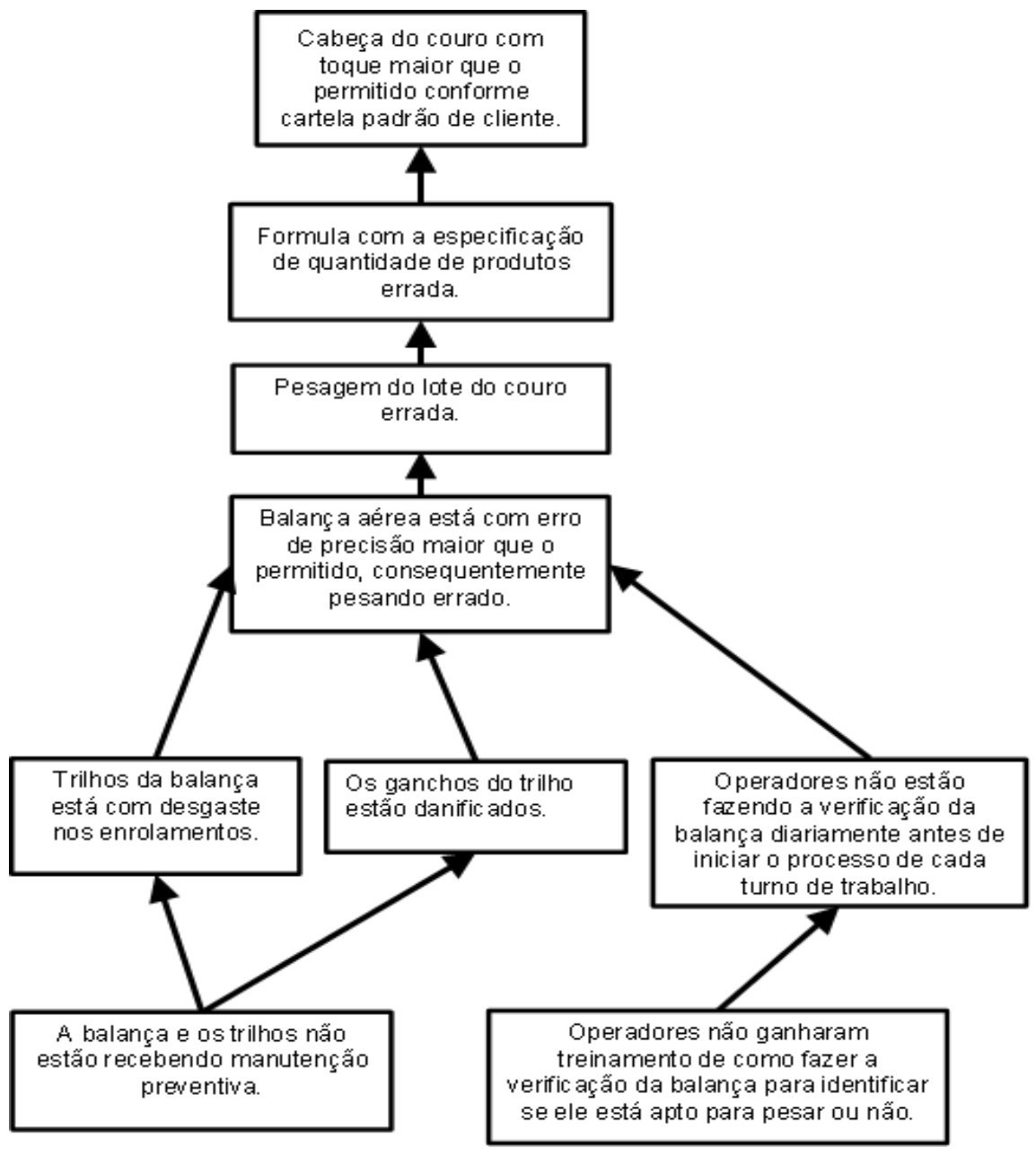

Figura 3. Árvore da Realidade Atual

Uma vez feita a identificação das possíveis causas encontradas no Diagrama de Ishikawa, posteriormente foi elaborada a ARA (Figura 3) relacionando as causas e efeitos, até encontrar as causas raízes que sendo solucionadas irão eliminar os efeito que se tornam o problema de maciez do couro prejudicial à qualidade.

Foram identificadas duas causas raízes. A primeira foi a balança e os trilhos aéreos não estão recebendo manutenção preventiva. Tais dispositivos tem o objetivo de impedir as falhas de enrolamento com desgaste e ganchos danificados. A segunda causa raiz identificada é que os operadores não possuem treinamento de como fazer a verificação da balança, para verificar se o equipamento está apto para realizar a pesagem ou não. Como resultados dessa etapa, e tendo as causas raízes encontradas elaborou-se o plano de ação para solucionálas. Assim, para fazer o desdobramento das ações utilizamos o relatório A3 (Tabela 2). 
Tabela 2. Relatório A3

\section{Título/Tema:}

Elaborar um plano de manutenção corretiva para a balança de trilhos aéreos. / Treinar os operadores para fazer a verificação da balança antes de começar o processo.

\begin{tabular}{|c|c|c|c|c|c|}
\hline 1. & Considerações iniciais & \multicolumn{4}{|c|}{ Estado/Futuro e recomendações } \\
\hline & $\begin{array}{l}\text { Elaborar um plano de manu- } \\
\text { tenção preventiva para ba- } \\
\text { lança e trilhos aéreos com o } \\
\text { objetivo de reduzir ou impe- } \\
\text { dir falhas no desempenho } \\
\text { de pesagem da balança. } \\
\text { Treinar os operadores para } \\
\text { fazer verificação da balança } \\
\text { com os pesos padrões para } \\
\text { identificar se a balança está } \\
\text { apta para pesagem, aumen- } \\
\text { tando a confiabilidade e leva } \\
\text { o equipamento a operar } \\
\text { com condições confiável. }\end{array}$ & \multicolumn{4}{|c|}{$\begin{array}{l}\text { Elaborar a manutenção preventiva afim de reduzir as falhas } \\
\text { do trilho e da balança, e fazer a verificação da balança pelos } \\
\text { operadores antes de iniciar o processo verificando se está } \\
\text { dentro da margem especificada, que é um erro }<2 \% \text {. }\end{array}$} \\
\hline 2. & $\begin{array}{l}\text { Metas, objetivos e bene- } \\
\text { fícios }\end{array}$ & 6. Plano de açã & & & \\
\hline \multirow{3}{*}{\multicolumn{2}{|c|}{$\begin{array}{l}\text { Ter um equipamento de pesagem } \\
\text { confiável, que possa trabalhar } \\
\text { dentro da margem de erro aceitável } \\
\text { que são os } 2 \% \text { de erro permitido } \\
\text { pela especificação do processo, } \\
\text { consequentemente eliminando o } \\
\text { problema de toque do couro e reduzir } \\
\text { o custo da não-qualidade que foi } \$ \\
21.800,00 \text {. }\end{array}$}} & Descrição & Responsável & Inicio & Fim \\
\hline & & $\begin{array}{l}\text { Elaborar plano de } \\
\text { manutenção preventiva } \\
\text { nos trilhos e balança } \\
\text { aérea. }\end{array}$ & $\begin{array}{l}\text { Valdecir } \\
\text { (Manutenção) }\end{array}$ & $21 / 11 / 2016$ & $01 / 12 / 2016$ \\
\hline & & $\begin{array}{l}\text { Treinar os operadores } \\
\text { a fazer a verificação da } \\
\text { balança. }\end{array}$ & $\begin{array}{l}\text { Qualidade } \\
\text { (Juliana) }\end{array}$ & $21 / 11 / 2016$ & $01 / 12 / 2106$ \\
\hline \multirow[t]{2}{*}{3.} & Estado atual & \multicolumn{4}{|c|}{ Acompanhamento/Indicadores } \\
\hline & $\begin{array}{l}\text { A balança tem um erro } \\
\text { maior que o permito pelo } \\
\text { processo que é } 2 \% \text {, ocor- } \\
\text { rendo problemas de curti- } \\
\text { mento do couro, como cou- } \\
\text { ro com toque maior do que } \\
\text { o especificado pelo cliente. }\end{array}$ & \multirow{3}{*}{\multicolumn{4}{|c|}{$\begin{array}{l}\text { A balança será verificada uma vez por semana, todo mês será } \\
\text { realizado no setor da classificação do produto acabado o relatório de } \\
\text { problemas acontecido mensalmente no processo interno, identificando } \\
\text { se problema não é reincidente. }\end{array}$}} \\
\hline \multirow[t]{2}{*}{4.} & Analise/Causas & & & & \\
\hline & $\begin{array}{l}\text { Não estão fazendo manu- } \\
\text { tenção corretiva na balança } \\
\text { e nos trilhos aéreos, con- } \\
\text { sequentemente as peças } \\
\text { chaves desses equipamen- } \\
\text { tos estão com falhas que } \\
\text { prejudicam impacta em uma } \\
\text { pesagem confiável. }\end{array}$ & & & & \\
\hline
\end{tabular}


Com o relatório A3 efetivado, foram detalhadas as ações corretivas para solucionar a causa do problema de toque de maciez do couro. Verifica-se no lado esquerdo do relatório A3, as etapas referente ao planejamento, e no lado direito estão as etapas de fazer, verificar e agir. Após a implementação dos planos de ações, será observado por um prazo de um mês ou mais, para verificar a eficácia. Uma das vantagens do A3 é permitir verificar se o plano de ação foi.

Após identificar as causas raiz desse problema, os resultados obtidos mostraram que no relatório de qualidade do período investigado, foi possível identificar que o problema da maciez do couro gerou $80 \%$ do custo de não-qualidade do período. Ações foram propostas visando reduzir ou impedir falhas no desempenho do equipamento de medição e de sua estrutura de transporte, tendo assim resultados que geram decisões não confiáveis.

Com essa análise e aplicação as ferramentas da gestão da Qualidade, do Lean e da Teoria da Restrições, foi possível conhecer as anomalias do processo e descobrir o problema com a maior frequência. A pesquisa permitiu, portanto, evidenciar para a empresa as causas raízes que até então, eram desconhecidas e geravam um custo alto para a empresa. Como resultado, foi elaborado um plano de ação para eliminar tais problemas, onde todas as etapas para implementação do plano de ação serão monitoradas.

Os resultados demonstraram que, em empresas de segmentos com baixa maturidade em ferramentas de gestão de da qualidade, como as empresas de beneficiamento de couro, é de extrema importância investigar a causa raiz dos problemas, visando reduzir os custos com retrabalhos e devoluções. As técnicas e ferramentas utilizadas nessa pesquisa, se mostraram ser eficientes na identificação, priorização e plano de ação para solucionar os problemas.

No período da realização do estudo, foram percebidas dificuldades na aceitação da implantação de controles quantitativos de qualidade na empresa. Tal fato ocorreu porque os operadores demonstraram uma rejeição ao conhecer um novo método, dado que precisariam fazer tarefas adicionas às que normalmente faziam.

Porém com o acompanhamento diário das atividades de implantação das melhorias e dos controles, foi possível medir e analisar as variáveis que podem influenciar na qualidade do curtimento do couro. Com a consolidação da rotinas desses controles, o engajamento dos funcionários do nível operacional melhorou a partir da percepção do impacto positivo nas realização das tarefas.

Os resultados dessa pesquisa são aderentes com estudos anteriores realizados no tema da qualidade. Packer e Sushi (2010), citam que o motivo que levam as empresas a mensurar os seus custos de qualidade, são os valores que não agregam qualidade no produto. $E$ após identificados tais valores e impactos financeiros, as empresas iniciam a identificar oportunidades de melhorias para reduzir esses custos.

Os resultados da pesquisa e das causas mapeadas na ARA, concordam com a classificação dos tipos de causas raízes sugeridas pela literatura. Por exemplo, Pasquini (2013), explica que existem dois tipos principais de custos. Os custos relacionados às falhas internas, que são todos aqueles acontecimentos devido a algum erro do processo produtivo, sejam elas falhas humanas ou mecânicas. $E$ os custos relacionas com as falhas externas, que são aquelas falhas no produto quando são achadas no mercado ou encontrados pelo consumidor final. Essa categoria, gera também custos intangíveis, como destruição da imagem e confiabilidade da empresa.

As ferramentas da qualidade, facilitam encontrar esses problemas e suas causas raízes, assim como quantificar o problema que está gerando o maior custo da não-qualidade. Portanto, assim, é possível realizar a melhoria continua da qualidade (Pacheco et al., 2011).

A realização do presente estudo, assim como as diretrizes indicadas por Paladini (1998), 
apontam as vantagens de aplicação do gráfico de Pareto para mapear o problema mais ocorrente no processo. Santos (2014), com a aplicação da metodologia A3, evitaram o uso de relatórios de difíceis visualização e longos, e de forma simplificada conseguiu monitorar os planos de ações. Tais benefícios também foram encontrados na empresa investigada em nosso estudo.

De forma geral, esse estudo demonstrou que as ferramentas utilizadas de diferentes áreas de estudo, como o Lean, a Teoria das Restrições e da qualidade foram úteis para o contexto das indústria de beneficiamento de couro. A combinação dessas ferramentas permitiu identificar as causas dos principais problemas que mais geraram custos no período analisado.

\section{CONCLUSÕES}

Esse artigo se propôs a reduzir os custos da não-qualidade em um sistema de produção de curtimento de couros em uma empresa brasileira. A pesquisa foi conduzida em uma empresa que vem enfrentando instabilidade financeira causadas pelos problemas de qualidade.

Dentre as principais implicações dessa pesquisa para o contexto empresarial, foi identificado que é de extrema importância que os conhecimentos dos colaboradores das empresas desse setor sejam aprimorados com novas técnicas de qualidade e produtividade. Tal tarefa pode ser conduzida com suporte do setor de recursos humanos que deverá analisar e desenvolver planos de médio e longo prazo para que não ocorra resistência a novas investigações de anormalidades da no processo. Assim sendo, essas portanto, algumas das contribuições que podem ser significativas para facilitar novas propostas de estudo ou técnicas.

Umas das limitações que podem ser consideradas nessa pesquisa foi a disponibilidade dos gestores para aplicar as ferramentas na empresa. Por esse motivo a aplicação dos estudos foi realizada em períodos alternativos, de acordo com a agenda dos gestores. Outra limitação mapeada, foi a falta de estudos específicos sobre a integração de ferramentas da qualidade, do Lean e da Teoria das restrições em empresas do setor de curtimento de couro.

Com a finalidade de dar seguimento a presente pesquisa, sugere-se que as aplicações dos estudos para mensurar os custos da não-qualidade sejam replicadas em outras empresas desse setor e também noutros seguimentos, permitindo que os resultados sejam comparados com os resultados da presente pesquisa.

\section{REFERÊNCIAS}

ALMEIDA, D. R. e MATIAS, N. T. (2016). Redução de reclamação de clientes em indústria de alimentos, utilizando ferramentas de qualidade - comparativo 2014x2015: estudo de caso. DI Factum 2016, v.1, n.1, pp.61-68.

ARANTES, S. H. A. e GIACAGLIA, O. E. G. Melhoria de resultados de confiabilidade dos equipamentos, pela aplicação do Hoshin Kanri, associado ao relatório A3. Em: Anais IX Congresso Nacional de Excelência em Gestão, Brasil, (2013).

BRANDI, D., MOREIRA, C. e CAMPOS, C. F. Relação entre a gestão do conhecimento e a metodologia do relatório A3 aplicado ao processo de padronização. Em: Anais Simpósio de 
Excelência em Gestão e Tecnologia, Resende, Brasil, (2012).

CAMPOS, G. R. (2016). Gestão dos custos da qualidade: diagnóstico do segmento moveleiro da região noroeste do estado do Paraná. Revista de Ciências Empresariais da UNIPARRECEU, v.16, n.2, pp. 231-244.

COCIORVA, A., SARAIVA, M.; NOVAS, C. J. e FERREIRA, O. En Margarida Saraiva e António Teixeira (ed.). TMQ - Qualidade: Gestão da Qualidade numa perspectiva multi e interdisciplinar n 1. Lisboa: Edições Sílabo, 2010, pp.151-182. ISSN: 1647-6263

COLETTI, J., BONDUELLE, M.G. e IWAKIRI, S. (2010). Avaliação de defeitos no processo de fabricação de lamelas para pisos de madeira engenheirados com uso de ferramentas de controle de qualidade. Acta Amaz, v. 40, n.1, pp. 135 - 140.

GODINA, R., PIMENTEL, C., SILVA, F.J.G. e MATIAS, J.C.O. (2018). Improvement of the Statistical Process Control Certainty in a Automotive Manufacturing Unit. 2018. Procedia Manufacturing [em linha]. 17, 729-736. Disponível em: 10.1016/j.promfg.2018.10.123

GONÇALVES, V. F. L. A redução de problemas de qualidade através da utilização do método ciclo PDCA: um estudo de caso na indústria cosmética. Em: Anais VII Congresso Nacional de Excelência Em Gestão, Brasil, (2011).

KIRNER, G. T. Benefícios, Fatores de Sucesso e Dificuldades da Implantação do Modelo MPS.BR. Mestrado em Ciência da Computação. Univ. Metodista de Piracicaba (UNIMEP). Piracicaba - SP, 2011.

LACERDA, P. D., RODRIGUES, H. L. e SILVA, C. A. (2011). Avaliação da sinergia entre a engenharia de processos e o processo de pensamento da teoria das restrições. Revista Produção, v.21, n.2, pp. 284-300.

LAKATOS, E. M. e MARCONI, M. A. Fundamentos de Metodologia Científica. 5. ed. São Paulo: Atlas, 2003.

NOVAES, T. M. Aplicação da árvore da realidade atual para a identificação de oportunidades de melhoria de uma unidade de pesquisa clínica. Dissertação de Mestrado, Universidade de São Paulo. Ribeirão Preto, 2015.

OLIVARES R. B. I., COSTA, B. L. D. e QUEIROZ, L. S. (2011). Jogos de empresa: aplicação à gestão da qualidade no ensino superior de química. Revista Quim. Nova, v.34, n.10, pp. 1811-1817.

OLIVEIRA, H. N. e NODARI, T. C. Metodologia do relatório A3 para a solução de problemas. Trabalho de Conclusão de Curso. Universidade Federal do Rio Grande do Sul, 2010.

OLIVEIRA, G. R., MOTTA, M. E. V., CAMARGO, M. E., TONDOLO, V. A. G. e ZANADREA, G., \& RUSSO, S. L. (2016). Redução dos custos da qualidade com melhoria dos processos: um estudo de caso. Revista GEINTEC-Gestão, Inovação e Tecnologias, v.6, n. 2, pp. 32413256.

PACKER, C. L. e SUSKI, C. A. Gestão à vista na produção como ferramenta de trabalho. Em: Anais I Congresso de Inovação, Tecnologia e Sustentabilidade. Brusque/SC, (2010).

PACHECO, M., SAMPAIO, P., RODRIGUES, C. Ferramentas da qualidade: estudo da sua aplicação e uso nas organizações portuguesas. Em: Anais Encontro Nacional de Engenharia e Gestão Industrial (ENEGI), Brazil, p. 237-239, (2011)

PALADINI, P. E. A base humanística da gestão da qualidade. Em: Anais ENEGEP [em linha]. 
(1998). Disponível em: http://www.abepro.org.br/biblioteca/ENEGEP1998_ART422.pdf

PASQUINI, N. C. (2013). Eliminação do custo da não qualidade. Revista Qualidade Emergente, v.5, n.1, pp. 45-58.

PINTO, S. J. L. e GOMES, S. J. Gerenciamento de custos que não agregam valor: evidências Geradas nos relatórios dos custos da qualidade de uma indústria Brasileira. Em. Anais: XVII Congresso de La Asociación Española de Contabilidad y Administración de Empresas, Espanha, (2011).

PERES, F. A. P. e FOGLIATTO, F. S. (2018). Variable selection methods in multivariate statistical process control: A systematic literature review. Computers \& Industrial Engineering [em linha], 115, 603-619. Disponível em: https://doi.org/10.1016/j.cie.2017.12.006

ROSA, H. B., LUZ, S. B. T., DIAS, B. S. R. e PERALTA, L. B. C. A abordagem Lean Healthcare: uma revisão bibliográfica sistemática. Em: Anais XXXVI ENEGEP, Brasil, (2016).

SILVA, P. C. P. e SEVERIANO FILHO, C. (2011). Ocorrência de custos ocultos em operações de serviços: insights sobre observação em uma sociedade de economia mista no Brasil. Gestão da Produção, v.18, n.3, pp. 499-508.

SILVA, S. E. C. e SASAKI, H. O. Análise de projetos de melhoria contínua desenvolvidos pelo método A3. Em: Anais XXXI ENEGEP, Brasil, (2011).

SOCCOL, P. A. e GOMES, S. T. (2011). O custo da não qualidade: um estudo de caso em uma empresa do ramo automobilístico. Revista CEPPG, v.25, n. 2, pp. 130-146.

VASCONCELOS, C. S. D., SOCORRO, M., SOUTO, L. M. e GOMES, B. L. M.; MESQUITA, M. A. A utilização das ferramentas da qualidade como suporte a melhoria do processo de produção - estudo de caso na indústria têxtil. Em: Anais XXIX ENEGEP. Brasil, (2009).

VRABIČ, G. S. R. e ALOJA, P. B. (2013). Statistical Process Control as a Service: An Industrial Case Study. Procedia CIRP [em linha], 7, 401-406. Disponível em: https://doi.org/10.1016/j. procir.2013.06.006 